\title{
Identification of novel Angiogenin ( $A N G)$ gene missense variants in German patients with amyotrophic lateral sclerosis
}

\author{
Rubén Fernández-Santiago $\cdot$ Sabine Hoenig $\cdot$ Peter Lichtner $\cdot$ Anne-Dorte Sperfeld $\cdot$ Manu Sharma \\ Daniela Berg • Oliver Weichenrieder - Thomas Illig · Katharina Eger - Thomas Meyer • \\ Johanna Anneser · Christoph Münch · Stephan Zierz · Thomas Gasser · Albert Ludolph
}

Received: 17 September 2008/Revised: 10 March 2009/Accepted: 23 March 2009/Published online: 12 April 2009

(c) Springer-Verlag 2009

\begin{abstract}
Amyotrophic lateral sclerosis (ALS) is a fatal progressive neurodegenerative disease characterized by the selective death of motor neurons in the motor cortex, brain stem and spinal cord. Recently, missense variants in the angiogenin gene $(A N G)$, an angiogenic factor expressed in ventral horn motor neurons that is up-regulated by hypoxia, have been found in ALS patients of Irish/Scottish, North American, Italian, French and Dutch descent. To investigate the role of ANG in the German population, we screened for mutations by sequencing the entire coding region of the ANG gene in a large sample of 581 German
\end{abstract}

Electronic supplementary material The online version of this article (doi:10.1007/s00415-009-5124-4) contains supplementary material, which is available to authorized users.

R. Fernández-Santiago · M. Sharma · D. Berg · T. Gasser Department for Neurodegenerative Disorders,

Hertie Institute for Clinical Brain Research,

Eberhard-Karls University, Tuebingen, Germany

T. Gasser

e-mail: thomas.gasser@med.uni-tuebingen.de

R. Fernández-Santiago

Graduate School of Cellular and Molecular Neuroscience, International Max Planck Research School,

Graduate Training Center of Neuroscience,

Eberhard-Karls University, Tuebingen, Germany

S. Hoenig · A.-D. Sperfeld · A. Ludolph ( $\square)$

Department of Neurology, University Hospital of Ulm,

Oberer Eselsberg 45, 89081 Ulm, Germany

e-mail: albert.ludolph@rku.de

\section{P. Lichtner}

Institute for Human Genetics, GSF-National Research Centre

for Environment and Health, Neuherberg, Germany
ALS cases and 616 sex- and age-matched healthy controls. We identified two heterozygous missense variants, $\mathrm{F}(-13) \mathrm{L}$ and K54E, in two German sporadic ALS cases but not in controls. Both missense variants are novel and have not been previously found in ALS cases. Our results suggest that missense variants in the $A N G$ gene play a role in ALS in the German population and provide further evidence to support the hypothesis that angiogenic factors up-regulated by hypoxia are involved in the pathophysiology of ALS.

Keywords Angiogenin - Missense variant . Amyotrophic lateral sclerosis (ALS)

O. Weichenrieder

Department of Biochemistry,

Max Plank Institute for Developmental Biology,

Tuebingen, Germany

T. Illig

Institute for Epidemiology, GSF-National Research Centre

for Environment and Health, Neuherberg, Germany

K. Eger $\cdot$ S. Zierz

Department of Neurology,

University Hospital Halle-Wittenberg, Halle, Germany

T. Meyer · C. Münch

Department of Neurology,

Charité Humbolt-University Hospital Berlin,

Berlin, Germany

\section{J. Anneser}

Department of Neurology, Grosshadern University Hospital, Ludwig-Maximilians University, Munich, Germany 


\section{Introduction}

Amyotrophic lateral sclerosis (ALS) is a neurodegenerative disease that specifically affects the motor neurons in the spinal cord, brain stem and motor cortex. To date, five ALS causative genes have been identified in patients with familial ALS, accounting for 5-10\% of all ALS cases. While autosomal dominant mutations in the $\mathrm{Cu} / \mathrm{Zn}$ superoxide dismutase (SOD1) [20], vesicle-associated protein B $(V A P B)$ [17], and dynactin [19] have been shown to cause adult-onset forms of ALS, mutations in senataxin (SETX) lead to an early onset of the disease [3]. In contrast, mutations in the gene encoding alsin have been associated with juvenile-onset autosomal recessive ALS [10, 24].

In addition, genetic variants in certain genes may play a role in modifying ALS susceptibility. Certain haplotypes in the vascular endothelial growth factor $(V E G F)$ gene have been reported to be a possible risk factor for sporadic ALS [16] in a population based study, whereas a recent metaanalysis has confirmed increased susceptibility for ALS in male carriers of the promoter single nucleotide polymorphism (SNP) -2578AA [15]. Subsequently, seven missense variants in angiogenin $(A N G)$, another angiogenic factor in the ventral horn motor neurons which is up-regulated by hypoxia, have been suggested to be associated with ALS in Irish/Scottish patients [9]. Other ANG missense variants have been identified in ALS patients from North America [23], Italy [4, 7], France [18] and the Netherlands [22]. In addition, recent functional studies have shown that $A N G$ missense variants identified in ALS patients lead to reduced angiogenic activity of ANG in endothelial cells [23], and impairment of neurite extension and survival in motor neurons [14, 21].

To investigate the role of $A N G$ in ALS patients from Germany, we screened for mutations by sequencing the entire coding region of the $A N G$ gene in a large cohort of German ALS patients and controls. We identified two novel heterozygous $A N G$ missense variants in two sporadic ALS cases but not in controls. Our findings suggest that missense variants in the $A N G$ gene play a role in ALS in the German population.

\section{Subjects and methods}

\section{Subjects}

Informed consent was obtained from 581 sporadic ALS patients and 616 healthy controls. Of these, 401 patients were referred to the Neurology Department of the University Hospital of Ulm, and 180 patients to the Neurology Department of the University Hospital Grosshadern (Munich). Samples from 365 age- and gender-matched healthy controls were obtained from the adult populationbased KORA study [13], whereas those from 251 gendermatched controls older than age 60 were obtained from our local DNA database. The ALS sample consisted of 581 sporadic ALS patients with clinical diagnosis of probable or definite ALS according to the revised El Escorial criteria $[1,2]$. The male to female ratio was 1.7 . Average age-atonset was 59 years and average survival time was 51 months. $70 \%$ of the patients had limb onset, $30 \%$ showed bulbar onset.

\section{Genetic analysis}

Genomic DNA was isolated from peripheral blood using standard protocols. The GenBank reference sequence accession number of $A N G$ was NM_001145.4. In the CDNA, the A of the ATG translation initiation start site was numbered as nucleotide +1 . In accordance with the literature, amino acids from the signal peptide of $A N G$ (24 aminoacids) were named in negative numbers whereas those from the processed protein (123 amino acids) were named in positive numbers, the first Gln residue of the entire sequence being numbered as amino acid +1 . Primers were designed using the ExonPrimer software (http:// ihg.gsf.de/ihg/ExonPrimer.html) for the $A N G$ coding region. PCR products were sequenced directly using the BigDye Terminator Cycle sequencing kit 3.1 (Applied Biosystems) and were analyzed on an ABI3730 sequencer. The following primers were used for PCR and sequencing: 5'-TGTTCTTGGGTCTACCACACC-3', 5'-ATGTTGCCA CCACTGTTCTG-3' (amplicon length: $583 \mathrm{bp}$ ). The complete $A N G$ coding region was sequenced for both case and control subjects from forward and reverse ends including the exon/intron junction.

Statistical analysis

The statistical analysis of the allelic frequency for SNP rs 11701 was conducted using the $\chi^{2}$ test with one degree of freedom.

\section{Bioinformatics}

Missense variants were mapped onto the three-dimensional crystal structure of the mature ANG protein using PyMOL software (Delano Scientific LLC).

\section{Results}

In our study, we identified two heterozygous $A N G$ missense variants in two ALS patients of German descent that were negative for mutations in the SOD1 screening 
(Table 1). A ca. $36 \mathrm{C}>\mathrm{T}$ transition located within the signal peptide of $A N G$ results in a $\mathrm{F}(-13) \mathrm{L}$ substitution whereas the ca. $232 \mathrm{~A}>\mathrm{G}$ transition causes a K54E amino acid substitution that affects the mature protein. The replacement of the basic Lys by the acid Glu in K54E is represented in Fig. 1. The missense variants $\mathrm{F}(-13) \mathrm{L}$ and $\mathrm{K} 54 \mathrm{E}$ are novel and have not been previously linked to ALS. Neither of these variants were found in 616 controls. Overall, the estimated mutational frequency of the $A N G$ gene is $0.3 \%$ in our population. Unfortunately, the segregation of missense variants $\mathrm{F}(-13) \mathrm{L}$ and $\mathrm{K} 54 \mathrm{E}$ could not be investigated further due to the unavailability of DNA from family members of the patients. However, none of the carriers had a familial history of ALS. The clinical picture of the $\mathrm{F}(-13) \mathrm{L}$ and $\mathrm{K} 54 \mathrm{E}$ carriers is summarized in Table 1.

Our results also identified the previously reported heterozygous missense variant I46V (ca. $208 \mathrm{~A}>\mathrm{G}$ ) in one ALS patient but not in controls. Originally, I46V was described in three Scottish ALS patients [9] and subsequently in two French cases [18]. Nonetheless, I46V has been suggested to be a benign variant, at least in the Italian population, because it was found in a total of 7 Italian patients and 11 healthy controls [4, 5, 7]. Furthermore, we identified the variant K17I (ca. $122 \mathrm{~A}>\mathrm{T}$ ) in one sporadic ALS case $(0.1 \%)$ and two controls (35/62 years of age) $(0.3 \%)$. This finding is in agreement with a previous study that identified K17I in two Irish/Scottish ALS patients and one control (65 years) [9]. In a Dutch pedigree, variant K17I was recently shown to segregate with disease following an autosomal dominant inheritance model with reduced penetrance [22]. Of the 17 different $A N G$ missense variants identified in ALS patients up to date (Table 1, supplemental data), only K17I and I46V were found in both cases and controls.

Examination of ANG evolutionary conservation showed that residues Phe(-13), Lys17, Ile46 and Lys54 are conserved in mammals (Fig. 1, supplemental data). None of the identified missense variants were exclusively present in controls.

The sequence analysis confirmed the presence of the common synonymous SNP rs11701 (T/G) in our population. This SNP was shown to be associated with ALS in the Irish population [9] in which the frequency of the allele $G$ was significantly higher in ALS cases compared with controls $(0.17$ vs. $0.09, P<0.001)$. Nevertheless, we did not find the association of this allele to disease as previously reported in the Irish/Scottish population (Table 2). In our sample, the distribution of the $\mathrm{G}$ allele was 0.12 in cases and 0.13 in controls $(P>0.05)$. The previously identified SNP rs17560 was not observed in our sample. However, we found the allele T of the SNP rs2228653 in one ALS case and none of the controls. This SNP is located 


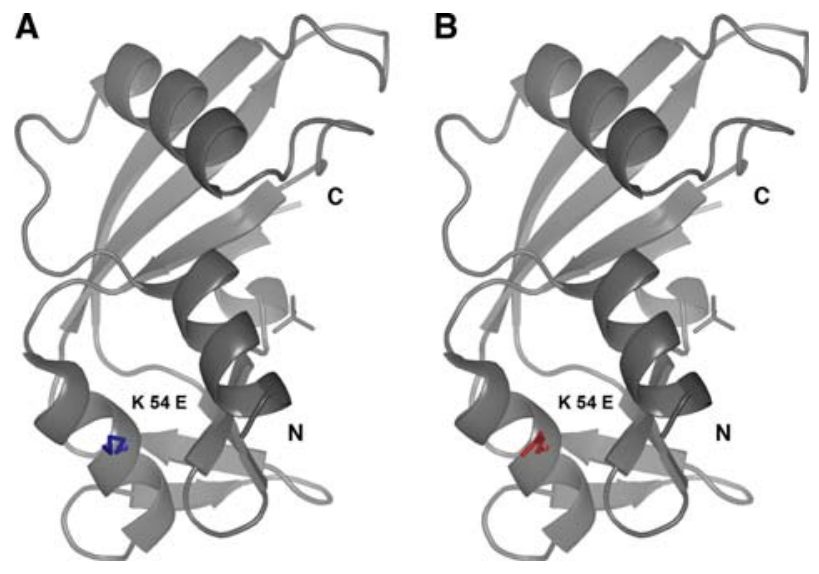

Fig. 1 Structure of angiogenin (PDB-ID 1h53). a, b Angiogenin is shown as ribbons with the phosphate near the active site and with the mutated residue shown as sticks. The K54 side-chain from the wildtype protein is in blue (a), the modeled K54E side chain is in red (b)

Table 2 Genotypic and allelic frequencies of synonymous SNP rs11701 in German ALS patients and controls

\begin{tabular}{lll}
\hline & Patients & Controls \\
\hline TT genotype & 0.768 & 0.747 \\
TG genotype & 0.217 & 0.235 \\
GG genotype & 0.015 & $0.018(P>0.05)$ \\
T allele & 0.876 & 0.864 \\
G allele & 0.124 & $0.136(P>0.05)$ \\
\hline
\end{tabular}

within the coding region of ANG and results in the synonymous substitution T97T, which makes it difficult to predict whether this synonymous variant is disease specific.

\section{Discussion}

$A N G$ was first suggested to be a susceptibility gene for ALS when the SNP rs11701, located within the coding region of the gene, was found to be significantly associated with disease in an Irish ALS cohort [8]. Subsequently, seven different heterozygous $A N G$ missense variants were identified in a large cohort of 1629 patients from Ireland, Great Britain, the USA and Sweden [9]. Although ANG missense variants were present in individuals from all four subpopulations, the majority of the affected individuals were of Irish/Scottish descent, suggesting that ANG might be a specific ALS susceptibility factor in the Irish/Scottish subpopulation. However, another study confirmed the occurrence of $A N G$ missense variants in an independent ALS cohort of North American descent [23]. Subsequently, novel ALS-associated $A N G$ missense variants were reported in one French [18], one Dutch [22] and two different Italian $[4,7]$ samples. In contrast, two additional Italian groups have failed to identify ANG missense variants in their ALS cohorts $[5,6]$. To date, no report has assessed the role of ANG in the German ALS population.

In our study, we sequenced the coding region of the $A N G$ gene in a German ALS cohort and in controls. Our sample, together with that of Gellera et al. [7], is the second largest sample studied after the one from Greenway et al. [9]. We identified two $A N G$ missense variants, $\mathrm{F}(-13) \mathrm{L}$ and K54E, in two ALS cases $(0.3 \%$; 2/581). Both ANG missense variants are novel and, to our knowledge, have not been previously documented. The variants $\mathrm{F}(-13) \mathrm{L}$ and $\mathrm{K} 54 \mathrm{E}$ appear to be disease-specific in our population, since both were absent in our 616 controls, as well as in 3107 controls that were sequenced in previous $A N G$ mutational screenings $[4-7,9,18,22,23]$. Our results indicate that the novel $A N G$ missense variants $\mathrm{F}(-13) \mathrm{L}$ and K54E are linked to ALS in the German population.

In the Scottish/Irish population, several $A N G$ missense variants have been suggested to segregate with familial and sporadic ALS [9]. However, segregation of $A N G$ missense variants has not been fully reproduced in other populations $[5,7,18,23]$ until the recent screening of a Dutch pedigree carrying the K17I missense variant [22]. In our case, the carriers of the ANG missense variants $\mathrm{F}(-13) \mathrm{L}$ and K54E were apparently 'sporadic' ALS cases without a family history of ALS. Both mutation carriers were male patients with predominant lower motor-neuron deficits and a reduced life expectancy of less than 3 years. The $\mathrm{F}(-13) \mathrm{L}$ carrier had a late age at onset (71 years), while the K54E carrier showed an early onset of disease (28 years). Interestingly, the K54E carrier showed clear signs of frontal deficit. Nonetheless, because the K54E carrier was deceased, we were unable to further characterize this patient clinically. Previously, a Dutch patient carrying the missense variant K17I presented ALS with frontotemporal dementia (FTD) [22], whereas another Italian SALS patient with a synonymous ca. $132 \mathrm{C}>\mathrm{T}$ variant had a diagnosis of frontal lobe dysfunction [7]. These findings are interesting because they suggest that ANG may also be involved in cognitive impairment.

$\mathrm{F}(-13) \mathrm{L}$ is located in the signal peptide of ANG, whereas K54E affects the mature ANG protein. Although the effects of these missense variants on the ANG protein are difficult to predict, we performed structural modeling of these variants in the 3-D crystal structure of the protein. We speculate that the $\mathrm{F}(-13) \mathrm{L}$ variant, located in the signal peptide of ANG which is involved in protein trafficking [12], might lead to abnormal protein transport and secretion or toan altered recognition site for the signal peptide peptidase, leading to mislocalization of ANG. In the case of the K54E variant, the replacement of a basic residue by an acidic glutamate disrupts a patch of positively charged protein surface formed by residues Lys50, 
Arg51 and Lys54 that might be of functional relevance for the interaction of ANG with negatively charged molecules like nucleic acids or other proteins.

To date, a total of 15 different $A N G$ missense variants have been exclusively identified in ALS patients but not in controls [4, 7, 9, 18, 22, 23], including the novel $A N G$ missense variants $\mathrm{F}(-13) \mathrm{L}$ and $\mathrm{K} 54 \mathrm{E}$ reported in this study. Altogether, these results clearly suggest that missense variants in the $A N G$ gene, although rare, are potentially causative of disease as recently suggested in discussions regarding other complex neurodegenerative diseases, including the glucocerebroside gene $(G B A)$ in Parkinson's disease (PD) [11].

There is increasing evidence that variants in the $A N G$ gene play a role in ALS pathophysiology. Recently, the $A N G$ missense variants K17I, S28N and P112L identified in ALS patients from North America have been shown to result in complete ANG loss-of-function by reducing angiogenesis due to defects in ribonuclease activity, nuclear translocation, or a combination of both [23]. In addition, an independent study has shown that human ANG is neuroprotective, whereas the ALS-associated ANG variants Q12L, C39W and K40I, which are located in the catalytic center of the protein, compromise neurite extension, pathfinding and survival of motor-neurons [14, 21]. These findings have been confirmed for K40I in another recent report [14]. Furthermore, ANG is highly expressed in the spinal cord ventral horn motor-neurons during both fetal development and adulthood [21].

In summary, we identified two heterozygous missense variants, $\mathrm{F}(-13) \mathrm{L}$ and $\mathrm{K} 54 \mathrm{E}$, in the $A N G$ gene of two sporadic ALS patients of German descent but not in controls. Our results suggest that the $\mathrm{F}(-13)$ and K54E $A N G$ missense variants are linked to ALS in the German population and support the hypothesis that angiogenic factors up-regulated by hypoxia are involved in the pathophysiology of ALS. Future functional studies will help to decipher the specific role of these $A N G$ missense variants in ALS.

Acknowledgments The authors thank the patients and family members for their participation. They also thank all collaborating investigators and physicians, Janaky Coomaraswamy for editorial help, as well as the KORA group (H. E. Wichmann (speaker), H. Löwel, C. Meisinger, T. Illig, R. Holle, J. John, and their coworkers) for the design and conduct of the KORA studies. Part of this work was financed by the German National Genome Research Net (NGFN).

\section{References}

1. Brooks BR (1994) El Escorial World Federation of Neurology criteria for the diagnosis of amyotrophic lateral sclerosis. Subcommittee on Motor Neuron Diseases/Amyotrophic Lateral
Sclerosis of the World Federation of Neurology Research Group on Neuromuscular Diseases and the El Escorial "Clinical limits of amyotrophic lateral sclerosis" workshop contributors. J Neurol Sci 124(suppl):96-107

2. Brooks BR, Miller RG, Swash M, Munsat TL (2000) El Escorial revisited: revised criteria for the diagnosis of amyotrophic lateral sclerosis. Amyotroph Lateral Scler Other Motor Neuron Disord 1:293-299

3. Chen YZ, Bennett CL, Huynh HM, Blair IP, Puls I, Irobi J, Dierick I, Abel A, Kennerson ML, Rabin BA, Nicholson GA, AuerGrumbach M, Wagner K, De Jonghe P, Griffin JW, Fischbeck KH, Timmerman V, Cornblath DR, Chance PF (2004) DNA/RNA helicase gene mutations in a form of juvenile amyotrophic lateral sclerosis (ALS4). Am J Hum Genet 74:1128-1135

4. Conforti FL, Sprovieri T, Mazzei R, Ungaro C, La Bella V, Tessitore A, Patitucci A, Magariello A, Gabriele AL, Tedeschi G, Simone IL, Majorana G, Valentino P, Condino F, Bono F, Monsurro MR, Muglia M, Quattrone A (2008) A novel Angiogenin gene mutation in a sporadic patient with amyotrophic lateral sclerosis from southern Italy. Neuromuscul Disord 18:68-70

5. Corrado L, Battistini S, Penco S, Bergamaschi L, Testa L, Ricci C, Giannini F, Greco G, Patrosso MC, Pileggi S, Causarano R, Mazzini L, Momigliano-Richiardi P, D’Alfonso S (2007) Variations in the coding and regulatory sequences of the angiogenin (ANG) gene are not associated to ALS (amyotrophic lateral sclerosis) in the Italian population. J Neurol Sci 258:123-127

6. Del Bo R, Scarlato M, Ghezzi S, Martinelli-Boneschi F, Corti S, Locatelli F, Santoro D, Prelle A, Briani C, Nardini M, Siciliano G, Mancuso M, Murri L, Bresolin N, Comi GP (2008) Absence of angiogenic genes modification in Italian ALS patients. Neurobiol Aging 29:314-316

7. Gellera C, Colombrita C, Ticozzi N, Castellotti B, Bragato C, Ratti A, Taroni F, Silani V (2008) Identification of new ANG gene mutations in a large cohort of Italian patients with amyotrophic lateral sclerosis. Neurogenetics 9:33-40

8. Greenway MJ, Alexander MD, Ennis S, Traynor BJ, Corr B, Frost E, Green A, Hardiman O (2004) A novel candidate region for ALS on chromosome 14q11.2. Neurology 63:1936-1938

9. Greenway MJ, Andersen PM, Russ C, Ennis S, Cashman S, Donaghy C, Patterson V, Swingler R, Kieran D, Prehn J, Morrison KE, Green A, Acharya KR, Brown RH Jr, Hardiman O (2006) ANG mutations segregate with familial and 'sporadic' amyotrophic lateral sclerosis. Nat Genet 38:411-413

10. Hadano S, Hand CK, Osuga H, Yanagisawa Y, Otomo A, Devon RS, Miyamoto N, Showguchi-Miyata J, Okada Y, Singaraja R, Figlewicz DA, Kwiatkowski T, Hosler BA, Sagie T, Skaug J, Nasir J, Brown RH Jr, Scherer SW, Rouleau GA, Hayden MR, Ikeda JE (2001) A gene encoding a putative GTPase regulator is mutated in familial amyotrophic lateral sclerosis 2 . Nat Genet 29:166-173

11. Hruska KS, Goker-Alpan O, Sidransky E (2006) Gaucher disease and the synucleinopathies. J Biomed Biotechnol 2006:78549

12. Hu G, Xu C, Riordan JF (2000) Human angiogenin is rapidly translocated to the nucleus of human umbilical vein endothelial cells and binds to DNA. J Cell Biochem 76:452-462

13. Illig T, Bongardt F, Schopfer A, Holle R, Muller S, Rathmann W, Koenig W, Meisinger C, Wichmann HE, Kolb H (2003) The endotoxin receptor TLR4 polymorphism is not associated with diabetes or components of the metabolic syndrome. Diabetes 52:2861-2864

14. Kieran D, Sebastia J, Greenway MJ, King MA, Connaughton D, Concannon CG, Fenner B, Hardiman O, Prehn JH (2008) Control of motoneuron survival by angiogenin. J Neurosci 28:1405614061

15. Lambrechts D, Poesen K, Fernandez-Santiago R, Al-Chalabi A, Del Bo R, Van Vught PW, Khan S, Marklund S, Brockington A, 
Van Marion I, Anneser J, Shaw C, Ludolph A, Leigh N, Comi G, Gasser T, Shaw PJ, Morrison K, Andersen P, Van den Berg LH, Thijs V, Siddique T, Robberecht W, Carmeliet P (2008) Metaanalysis of VEGF variations in ALS: increased susceptibility in male carriers of the -2578AA genotype. J Med Genet. doi: 10.1136/jmg.2008.058222

16. Lambrechts D, Storkebaum E, Morimoto M, Del-Favero J, Desmet F, Marklund SL, Wyns S, Thijs V, Andersson J, van Marion I, Al-Chalabi A, Bornes S, Musson R, Hansen V, Beckman L, Adolfsson R, Pall HS, Prats H, Vermeire S, Rutgeerts P, Katayama S, Awata T, Leigh N, Lang-Lazdunski L, Dewerchin M, Shaw C, Moons L, Vlietinck R, Morrison KE, Robberecht W, Van Broeckhoven C, Collen D, Andersen PM, Carmeliet P (2003) VEGF is a modifier of amyotrophic lateral sclerosis in mice and humans and protects motoneurons against ischemic death. Nat Genet 34:383-394

17. Nishimura AL, Mitne-Neto M, Silva HC, Richieri-Costa A, Middleton S, Cascio D, Kok F, Oliveira JR, Gillingwater T, Webb J, Skehel P, Zatz M (2004) A mutation in the vesicletrafficking protein VAPB causes late-onset spinal muscular atrophy and amyotrophic lateral sclerosis. Am J Hum Genet 75:822-831

18. Paubel A, Violette J, Amy M, Praline J, Meininger V, Camu W, Corcia P, Andres CR, Vourc'h P (2008) Mutations of the ANG gene in French patients with sporadic amyotrophic lateral sclerosis. Arch Neurol 65:1333-1336

19. Puls I, Jonnakuty C, LaMonte BH, Holzbaur EL, Tokito M, Mann E, Floeter MK, Bidus K, Drayna D, Oh SJ, Brown RH Jr, Ludlow
CL, Fischbeck KH (2003) Mutant dynactin in motor neuron disease. Nat Genet 33:455-456

20. Rosen DR, Siddique T, Patterson D, Figlewicz DA, Sapp P, Hentati A, Donaldson D, Goto J, O'Regan JP, Deng HX et al (1993) Mutations in $\mathrm{Cu} / \mathrm{Zn}$ superoxide dismutase gene are associated with familial amyotrophic lateral sclerosis. Nature 362:5962

21. Subramanian V, Crabtree B, Acharya KR (2008) Human angiogenin is a neuroprotective factor and amyotrophic lateral sclerosis associated angiogenin variants affect neurite extension/pathfinding and survival of motor neurons. Hum Mol Genet 17:130-149

22. van Es MA, Diekstra FP, Veldink JH, Baas F, Bourque PR, Schelhaas HJ, Strengman E, Hennekam EA, Lindhout D, Ophoff RA, van den Berg LH (2009) A case of ALS-FTD in a large FALS pedigree with a K17I ANG mutation. Neurology 72:287288

23. Wu D, Yu W, Kishikawa H, Folkerth RD, Iafrate AJ, Shen Y, Xin W, Sims K, Hu GF (2007) Angiogenin loss-of-function mutations in amyotrophic lateral sclerosis. Ann Neurol 62:609-617

24. Yang Y, Hentati A, Deng HX, Dabbagh O, Sasaki T, Hirano M, Hung WY, Ouahchi K, Yan J, Azim AC, Cole N, Gascon G, Yagmour A, Ben-Hamida M, Pericak-Vance M, Hentati F, Siddique $\mathrm{T}$ (2001) The gene encoding alsin, a protein with three guanine-nucleotide exchange factor domains, is mutated in a form of recessive amyotrophic lateral sclerosis. Nat Genet 29:160-165 